\title{
True Love and Time Pass: Sexual Behavior of Metropolitan Slum Youth in India
}

Singh SK*, Nidhi Sharma, Sudipta Mondol and Ankita Siddhanta

International Institute for Population Sciences, Mumbai, India

\begin{abstract}
Today's youth is fast changing and developing rebel to conservativeness of society. Their attitude is shifting from romantic relationship to casual sex. West influenced societal norms and liberal sexual culture in metros offers varied avenues for sexual experiences adding opportunity for sexual liaisons. In the present study, we report findings derived from a study in the slums of Mumbai with a randomized cluster sample of 1239 men aged 18-29 using indepth interviews and survey. Results show, $80 \%$ of romantic relationships are translated to sexual relations. $10 \%$ of respondents reported multi-partner behavior in last one year and $1 / 5^{\text {th }}$ of respondents reported their "girlfriend" as married. Study reveals that peer network, self assessment as sexual partner and perceived relational satisfaction with girlfriend are significantly affecting safe sexual behavior and coercive sex. Multi-partner behavior is affecting condom use negatively, but catalyzing alcohol use and coercive sex. Findings facilitate understanding of changing sexual culture and behavior, growing liberal sexual attitude and increased vulnerability among the youth. Programmes to fully inform and equip youth to make safe choices is required for ramification of sexual risk behaviour and the interface of alcohol use and risky sexual behavior especially in casual relations.
\end{abstract}

Keywords: Romantic relationships; Sexual behavior; Sexual risk; Partner progression; Substance abuse; Perceived relational sexual satisfaction

\section{Introduction}

Romantic and sexual relationships are central to the lives of adolescents and youth. The development and negotiation of romantic relationships is considered an important and normative developmental task of growing up [1] with the emergence of, and experimentation with, sexual behaviors are integrated in to romantic relationships as age develops [2]. Sex is part of a healthy life, and developing an interest in sex is natural as younger teens undergo hormonal and other physical changes and older teens begin to take on young adult roles [3-8]. Although there is no clear age at which sexual activity becomes appropriate, the third National Family Health Survey (NFHS-3) in India has shown that the age of sexual debut of men and women have been 20.64 and 18 years, respectively [9]. The reported age of sexual debut of Indian youth is in general higher than their developed country counterparts. However, there is a declining trend in the recent years. With declining age of sexual debut, the sexual behavior of youth is also changing fast. Sex is no longer a taboo $[10,11]$ confined within the ambit of marriage. The pre-marital sex is increasingly common among youth. This is not only true among couples who are in an emotional bond. The casual sexual encounters are also widespread among youth. The anecdotal references or also popular culture often touch upon this issue. 'Friends with a benefit' or 'one night stand' is no longer foreign to youth in large metropolises in India.

\section{The Indian scenario}

As per the NACO (2010-11), India is estimated to have 2.39 million people infected with HIV in 2009 at an estimated adult HIV prevalence of $0.31 \%$ which was $0.32 \%$ in 2008 . This has made India the country with third largest number of people living with HIV/ AIDS among which $39 \%$ are female and $4.4 \%$ are children. Among the states, Manipur has shown the highest estimated adult HIV prevalence (1.40\%), followed by Andhra Pradesh (0.90\%), Mizoram (0.81\%), Nagaland $(0.78 \%)$, Karnataka $(0.63 \%)$ and Maharashtra $(0.55 \%)$.
Again within Maharashtra, the prevalence among the males is $0.64 \%$ and among the females it is $0.45 \%[12,13]$. Prevalence of Sexually Transmitted Infections (STIs) among men in India aged 15-49 and who have ever had sex is $5 \%$ and especially it is $7-10 \%$ in the young age group of 15-24 [9].

Premarital partnerships among youth, including those not engaged in sexual relationship, are widely discouraged in India [14-20]. Yet, despite strict sanctions, including parental control often through strict vigilance and physical violence, up to $10 \%$ of young women and $15-30 \%$ of young men form such partnerships [14]. A review of literature on the topic suggests that little is known about the nature of these relationships, such as whether they are romantic or casual $[14,20]$. Recent studies of sexuality in India show that pre-marital sex is not as rare as generally believed to be [21-26] and that young people often lack adequate information in order to protect themselves from sexually transmitted infections [27,28] and unwanted pregnancies. Singh et al. [29], found that unmarried men in Mumbai Slums are 1.5 times more likely to have sexual intercourse with women other than their girlfriends than their married counterparts and also the amount of alcohol consumed (predicted by level of childhood drinking exposure) is related to the number of non-exclusive (neither wife nor girlfriend) sexual partners among this Mumbai youth. Interestingly the youth do not constitute a homogenous category and the sexual attitude, experiences, experimentations and extent of vulnerability differ within the group.

*Corresponding author: Singh SK, International Institute for Population Sciences, Mumbai, India, Tel: 919869431429; E-mail: sksingh1992@yahoo.co.in

Received May 09, 2014; Accepted September 18, 2014; Published September 25,2014

Citation: Singh SK, Sharma N, Mondol S, Siddhanta A (2014) True Love and Time Pass: Sexual Behavior of Metropolitan Slum Youth in India. J AIDS Clin Res 5: 341 doi:10.4172/2155-6113.1000341

Copyright: @ 2014 Singh SK, et al. This is an open-access article distributed under the terms of the Creative Commons Attribution License, which permits unrestricted use, distribution, and reproduction in any medium, provided the original author and source are credited. 


\section{Why Youth in Low Income Communities Need Focus}

According to social cognitive theory people learn how to perform new behaviors by observing others and will imitate the behaviors they have observed in so far as those behaviors are perceived to have functional value. Sexuality in Indian society is seen as a cultural construct, which differs with age, social class and gender, division of labor, freedom of social life, moments and kinship arrangements. Further, in low income communities of metropolitan cities, there is a mix of traditional and modern values norms and practices regarding sexuality and sexual behavior, especially among youth. The low income communities in metropolitan areas are also known for overcrowded living conditions resulting in relaxation of restrictive social norms and sexual segregation. The metropolitan context also exposes young people to liberal sexual culture, offers variety of sexual avenues and provides anonymity that largely enhances the opportunity for sexual liaisons [30,31]. In addition, opportunity structures of low income slums in metropolitan cities, where youth have easier access to erotic materials influence articulation of their sexuality mainly through enhanced indulgence with different type of sexual partners in continuously expanding sexual networks. With modernity and the influence of mass media, the socio-cultural milieu has been changing fast. Adolescents and youth are now often more tempted to have sex even before marriage.

\section{Study Objectives}

The present research. aims to study the current pattern of romantic and sexual relationships among unmarried male youth in a low income setting of a large metropolis in India. It also intends to throw light on the changing attitude and behavior of these youth towards romantic and casual relationships and examine the factors that shape their attitude and behavior

\section{Data and Methods}

The study has used both qualitative and quantitative information from a community based survey as part of a National Institute on Alcohol Abuse and Alcoholism sponsored project entitled "Alcohol Use, Sexual Health Risks and HIV Prevention among Young Men in Low Income Communities in Mumbai, India" conducted under the auspices of International Institute of Population Sciences (IIPS), Mumbai with Institute for Community Research and University of Connecticut Health Center (UCHC), Connecticut, USA as partners. The cross-sectional survey data was collected over a span of 4 years from September 2005 to August 2009. The present paper has used data from 54 in-depth interviews and 1239 quantitative face to face interviews with young men aged 18 to 29 selected from three low income slum communities using randomized clustered sampling technique. The study collected comprehensive information on different dimensions of youth behavior including their perception about sex and sexuality, intimate relationships and premarital sex, masculinity, alcohol use and its linkages with different types of risk taking behaviors. The information was collected through a triangulated effort by integrating ethnographic, qualitative and quantitative techniques. The findings were further substantiated using narratives from the respondents. Further, a number of psychological scales have been used towards an attempt to capture various dimensions of relational satisfactions. The study has also used Guttmann's scale by merging a series of statements about concerning indicators after testing for reliability. In the current study, the romantic relationship as opposed to casual ones is conspicuous by the presence of 'emotional attachment' and 'long-term commitment'.

In order to capture various dimensions of relational satisfaction and behavioral profile, a number of psychological scales have been used, where information on different components of those scales were collected mostly on a five point scale as part of quantitative survey by mixing direction of those statements as a strategy to minimize stereotype. Subsequently, those items were converted in scales after changing direction of various statements and testing their reliability based on intra-class correlation coefficients. A brief description of these variables and scales is presented below. All these were computed by recoding a continuous Guttmann's scale created by merging statements concerning exposure to the variables of interest canvassed mostly on 5 point scale after testing of reliability and normalizing the scale.

\section{Condom Attitudes}

It was computed by recoding a continuous Guttmann's scale developed by merging a series of statements concerning different attitude towards condom use. Seven yes-no items (will you always use condom if you have extra-marital sex, condoms can prevent sexually transmitted disease, condoms can prevent conception, condoms can tear, condoms are only for use with sex workers, condoms reduce the pleasure of sex \& when a man drinks, it is hard to remember to use a condom) were classified as risky (1) or not (0). The index is categorised into three groups, low, moderate and high.

\section{Self-assessment as a sexual partner}

It was computed by recoding a continuous Guttmann's scale (very true, true, somewhat true, not true and not at all true) created by merging seven statements (you are a good sexual partner, your sex life meets your expectations, your sex life is very bad compared to most, you feel happy when you think about your sexual experiences, you are disappointed about the quality of your sex life, you are worried about your sex life and you feel happy about your sexual relationships). The continuous scale has been converted in three categories: not satisfactory, somewhat satisfactory and satisfactory.

\section{Communication relationship with girlfriend}

It was computed by recoding a continuous Guttmann's scale (never, rarely, sometimes, often, always) created by merging six statements (does your lover understand your moods?, your lover/girlfriend listens to your suggestions, your lover/girlfriend is sympathetic to your problems, your lover/girlfriend asks your opinions on different issues, you discuss freely about sex with your lover/girlfriend, you share your feelings freely with your lover/girlfriend) concerning communication relationship with lover/girlfriends. The continuous scale has also been converted in three categories of less open, moderately open and more open.

\section{Relationship satisfaction with girlfriend}

It was computed by recoding a continuous Guttmann's scale (very true, true, somewhat true, not true and not at all true) created by merging seven statements (you are better at your relationship with your girlfriend than most other people are with their relationships, you feel happy about your relationship, your needs are not satisfied in your relationship, you feel discouraged about your relationship, you are very satisfied with your relationship, you feel sad when you think about your relationship and your relationship with your girlfriend/lover is very bad compared to most) concerning relationship with girlfriend. The index has been classified into two categories: satisfied and not satisfied.

\section{Hyper masculinity}

It was computed by recoding a continuous Guttmann's scale 
(very true, true, somewhat true, not true and not at all true) created by merging eighteen statements (you can demand sex and receive it whenever you want it, you are always ready for any work, you would always be able to satisfy your sexual partners, you can produce male children, you can fulfil the economic needs of your family, you can have sexual intercourse several times in one night, you can drink daaru ${ }^{*}$ as you wish, you can make enough money to provide a good home for your family, you will play cards whenever you wish to, you can do as you please, you know what is wrong and what is right, you always say the right things, you would never allow a woman to take the initiative for sex, you would never allow your wife/lover to work out of home, you would never allow your wife/lover to interfere in your decisions, you alone would decide on the method of contraception, you would not allow your wife/lover to walk in the community without a burkha ${ }^{* * /}$ dupatta $^{* * *}$ and you alone would decide on children's schooling matters) concerning man's right to control over dimensions of household life. The continuous scale has also been converted in three categories: low, medium and high.

\section{Results and Discussion}

\section{Profile of the respondents}

There is no dearth of evidence suggesting that sexual behavior of young women and men vary by their background characteristics, such as age, marital status, religion, and caste, as well as the characteristics of the households to which they belong to including wealth status. Additionally, education and media exposure are important catalysts for both alcohol consumption and sexual behavior. This section presents the demographic and socioeconomic characteristics of the respondents included in the study.

\section{Socio-demographic profile}

The age distribution of the respondents is given in three agegroups i.e. 18-20 years, 21-24 years and 25-29 years. Overall, half of the respondents belonged to 25-29 age group. Almost one-third of them were in the age group 21-24 and only 18 percent were between $18-20$ years of age. Information about the marital status of the individual respondent is presented under three categories i.e. 'married living with wife', 'married not living with wife' and never married/ widowed/ divorced, separated or deserted. Since the number of widowed/ divorced, separated or deserted respondents was very small (only 3 ) such respondents were clubbed with the never married category. Forty percent of the respondents were never married. A little over one fifth (21 percent) of married respondents were not living with their wives at the time of the survey. The distribution of the respondents by duration of their stay in the present community revels that almost one-third of respondents ( 30 percent) were living in these communities of stay since birth and 28 percent had been living there for ten years or more. The remaining, over four tenths of respondents reported to live in the study communities since the last 0-9 years. Overall, only one in five respondents was a recent migrant, defined as living in the community since the last $0-4$ years. The educational attainment in any society is an important indicator of its level of socioeconomic development. Education also enhances the ability of individuals to achieve desired demographic and health goals. The distribution of respondents by their completed years of education reveals a low overall educational attainment among men in these three communities. Overall, 15 percent of men aged 18-29, have no education and an additional 19 percent of men have completed only primary school. Only 12 percent of young men aged 18 to 29 in low income communities have 10 or more years of education. A large majority of men in these communities (overall 80 percent) are Hindu followed by Muslim (11 percent) and Buddhists and others ( 8 percent). A majority of respondents in the three communities have high level of media exposure (62-77 percent). In total, almost one-third of the respondents included in the study were factory workers and almost one-fifth workers were drivers. Overall, a little more than half of the respondents (53 percent) were living in the "rented" houses. A sizable proportion of the respondents lived in extreme crowding conditions. Nearly one-third of the respondents lived in houses where the number of persons per room was more than four persons. Information was collected on variety of household assets such as cooking gas, iron, refrigerator, television, bicycle, moped or scooter or motor cycle, auto rickshaw, bed, table, chairs, cupboard, and sewing machine. Using this information 'Standard of Living' Index was calculated. Overall, more than half of the respondents in the three communities (53 percent) were included in the low standard of living category, 36 percent in medium standard of living and 10 percent in households with highest standard of living (Table 1).

\section{Behavioral profile of respondents}

Leisure time activities are important as they directly influence the peer group and immediate interaction milieu of a person. This is very important from intervention planning point of view as the amount of time spent and kind of leisure time activities can be used potentially for implementation and carrying out youth interventions using the peer based model, which are quite successful and effective in such groups. Overall 21 percent respondents have reported to be not engaged in any leisure time activities and 53 percent reported to be engaged in one or two activities. Further, 5 percent of respondents have reported that they are highly exposed to sexual stimuli and 25 percent young men in the study communities possess high hyper masculinity. Percentage of respondents reporting high hyper masculinity is highest (29 percent) among those with age below 21 years followed by the respondents of

\begin{tabular}{|c|c|c|c|}
\hline Characteristics & Total & Characteristics & Total \\
\hline \multicolumn{2}{|l|}{ Age (years) } & Religion & \\
\hline Below 21 & 17.60 & Hindu & 80.40 \\
\hline $21-24$ & 32.40 & Muslim & 11.10 \\
\hline 25 and above & 50.00 & Buddhist and Others & 8.40 \\
\hline \multicolumn{2}{|l|}{ Marital Status } & Standard of living & \\
\hline Married Living Wife & 39.20 & Low & 53.40 \\
\hline Married Not Living Wife & 21.10 & Medium & 36.30 \\
\hline Never married/others & 39.70 & High & 10.30 \\
\hline \multicolumn{2}{|l|}{ Duration of Stay } & Occupation & \\
\hline Since birth & 30.30 & Rock breaker/loader/construction & 12.80 \\
\hline $0-4$ years & 19.90 & Driver & 19.20 \\
\hline $5-9$ years & 21.60 & Contractor/self home & 6.40 \\
\hline 10 years and above & 28.20 & Factory worker & 31.70 \\
\hline \multicolumn{2}{|l|}{ Years of Schooling } & Government & 1.00 \\
\hline None & 14.60 & Other & 28.80 \\
\hline $1-5$ & 19.10 & \multirow{2}{*}{ Exposure to mass media } & \\
\hline $6-8$ & 29.70 & & \\
\hline $9-10$ & 24.80 & Low & 4.00 \\
\hline \multirow[t]{2}{*}{10 and more } & 11.80 & Moderate & 25.30 \\
\hline & & High & 70.60 \\
\hline \multicolumn{2}{|l|}{ Ownership of house } & Average no. of persons per room & \\
\hline Rented house & 52.90 & Less than three & 25.70 \\
\hline \multirow[t]{2}{*}{ Own house } & 47.10 & Three to four & 42.50 \\
\hline & & More than four & 31.70 \\
\hline
\end{tabular}

Table 1: Socio- demographic profile of the respondents. 
age 21-24 (28 percent). Unmarried men (29 percent) seize high hyper masculinity compared to married men. Among all the occupational groups, hyper masculinity is high among contractors and self-home workers (35 percent) followed by factory workers and others $(27$ percent). Exposure to mass media is negatively and leisure time activity is positively associated with high hyper masculinity. Men who are less exposed to mass media (39 percent) possess high hyper masculinity and men engaged with three or more leisure time activities ( 31 percent) seize high hyper masculinity. It is to be noticed that respondents whose level of drinking is low, among them hyper masculinity is high (27 percent). Again young men who are less exposed to sexual stimuli and pornographic materials possess high hyper masculinity (26 percent and 28 percent respectively). Among men who are engaged with their wives, hyper masculinity is low compared to those who are engaged with girl-friends and other types of partners. Yet again, young men whose condom attitude is low and who have not used condom in their last sexual encounter possess high hyper masculinity ( 30 percent and 26 percent respectively). Men who are suffering from sexual health problems possess more than three times high hyper masculinity than those who do not have any sexual health problems. Overall, a high attitude towards condom is very low (3 percent). Only 10 percent respondents used condom in their last sexual encounter. Sexual health problems in these communities are serious matters of concern. In all more than 80 percent respondents reported suffering from sexual health problems. Interestingly, the most crucial indicator for sexual health and STI/HIV prevention, condom use seemed to reduce a little with increasing number of partners. This can be due to risk perception and attitude towards safe sexual behavior. With second girlfriend, 54\% men reported of not using condom in the last sex. The same figure further rose to 56 with third and fourth partner.

\section{Substance abuse and coercive sex among respondents}

The most common form of tobacco being used in all the study communities is Gutka/chewing tobacco/mawa (65 percent). However, the use of Ganja/cannabis is seen to be very less in these communities with only 2.5 percent respondent using it. With increasing age tobacco use in all forms is also showing an increasing trend. Educational attainment is playing a significant role for tobacco use as higher education is resulting into low tobacco consumption. Except bidi/ cigarettes, all the other forms of tobacco are highly used by the respondents who are married and not living with their wives. If we divide the tobacco use in two categories namely use of smokeless and smoking tobacco, it is noticed that use of smokeless tobacco of both pan with tobacco (53 percent) and Gutka/chewing tobacco/mawa (77 percent), are consumed by relatively larger proportion of rock breakers/ loaders/constructions, whereas, the proportion of smokers is higher among drivers (33 percent). Contractors and self-employed workers, who seem to be economically better off than those reporting other two occupational groups, are more likely to use Ganjja (5 percent). It is observed that respondents' migratory status and tobacco use are positively associated. For example, percentage of respondents using pan with tobacco and whose duration of stay in the communities is 5-9 years is two times higher (58 percent) than those who have been staying in the communities since birth (29 percent).

Alcohol use was also high as $21 \%$ respondents reported to have ever had alcohol with their partners before sex and 17\% reported that they usually consumed alcohol with their partners before sex. One out of every ten men reported ever had forced sex with his partner which indicated high level of coercion in these type of relationships. One of the narratives portraying a form of coercive sex was reported by a respondent as "She was studying in a college. I told her that today she would be absent from her college.... We went in a garden. I bought her cold drink 'Pepsi' and mixed few tablets in it. After consuming cold drink she came closer to me and in five-ten minutes she started kissing me... I took her to a nearby lodge and rented room for 8 hours...she was very excited... may be because of pills...we had sex thrice... I used condom all the time."

The similar behavior when studied for second, third and fourth partners revealed that alcohol use increased from 11 to 14 percent. Coercive sex also increased from 9 to 11 percent in case of subsequent partners.

\section{Sexual and emotional relationships of the respondents}

Forty percent men reported to ever had sex with a girlfriend. This highlights the high prevalence of premarital sex in this group which is based on the emotional relationships. Nonetheless, if we see the recent sexual behavior, 22 percent men reported to have girlfriend currently. Interestingly, 80 percent of these relationships reported to result in sex. Further, ten percent of these men reported sex with more than two girlfriends in last one year. From the analysis of the type of relationship with this sexual partner who was termed as girlfriend, it was noted that there is further typology in this relationship which also decides the emotional and sexual intentions of the relations. Out of all these men who reported to have sex with girlfriend in the last one year, onefourth of these relationships were with a relative, neighbor or with a co-worker. Such relationships had no emotional thread attached to it. They were largely for sexual benefits. One of the respondent reported, "I had my first penetrative sex at the age of 17 with a girl who was working in my factory and that was my first sexual experience."

\section{Partnerships and sexual relations}

Results of this study revealed that three out of four romantic relationships are resulting into sexual intercourses. The narratives show that the emotional quotient in these relationships is not the basis for sex. One of the respondents who reported to have sex with his girlfriend in second meeting quoted "She was looking very sexy but her complexion was dark. I thought that sex doesn't see the color". Another respondent said, "My first penetrative sexual experience happened at the age of 18 and it happened with a girl who was staying adjacent to my house... I asked her for a friendship but my friends always said what is just friendship, do sex with her and one day in the village field I did, first time with her...now she is married and stays in another city...". Another interesting finding that emerges from this analysis is the sexual mix of young men with married women and the wide prevalence of casual sex. This can be substantiated with the fact that 22 percent of the reported "girlfriends" of these men were married and living with their husbands. But for these respondents, the sex with the women had no intension to a long term commitment. It just bordered more or less on being "friends with benefits". A narrative showing such relationship was reported by a 21 year old man. He said, "There is a married woman in my neighborhood. She always used to stare at me......one day when I saw that she was alone in her house then I went to her house and started talking to her for the first time. I immediately held her and said that I love you very much and I kissed her. She also told me that she also loved me very much and said to me that she wanted to have sex with me as her husband does not satisfy her and fulfill her sexual needs." Another respondent reported, "I had sex with my second girlfriend and not with the first. Although, I intended to have sexual intercourse with my first girlfriend also and she was interested to have it as was evident from her indulgence in touching and kissing during our interactions. But we did not get the opportunity. At that time, one day my 
second girlfriend informed me that her parents went out for the whole day and were likely to return only in the late evening. I did not have any intention to have sex with her when I met her. I was not at all prepared for sex. But after listening to her that her parents won't be in the house, I got ready. And we had sex in her house." Another respondent reported that 'I want to enjoy before marriage. There are about 8-10 girls in my area to whom I often visit and have sex with them.... that the girls are faithful to me. They don't have other relationships. I hardly use condom with them."

\section{Perceived relational satisfaction}

The table below shows the effect of perceived relational satisfaction from girlfriends as well as self-assessment as a sexual partner on three core indicators of sexual association viz. condom use attitude, sexual partners in the last 12 months and coercive sex in the last 6 months. The main highlights from the table reveal that more satisfaction with girlfriend is translating into better sexual behaviors in terms of having fewer sexual partners and less coercion in sex but at the same time it also shows negative impact on condom use behavior. The better communication with girlfriend has an effect on condom use and having multi partner positively as more open relationship is resulting into more positive attitude towards condom use whereas coercive sex is moving in the opposite direction. Interestingly, moderate open relationships present positive outcome in terms of all the three indicators. A person's self-assessment as sexual partner can also have strong bearing on the way he behaves. This is evident from the table below where number of sexual partners and coercive sex are severely affected by this. Being satisfied by self is resulting in a reduction of multiple partners and less indulgence in coercive sex. This may be a result of increased confidence with lesser need for sexual experimentations that usually encourage men to go to partners of unknown identity and thus result into having multiple sexual partners.

\section{Partner progression correlates}

As one moves from having relationship with one partner to many, risk increases. Transition from one to another partner was based on the perceived relational satisfaction along with perceived risk and the concept of fun and freedom. Those respondents who reported more than one girlfriend also displayed dissimilar risk behavior with these partners. The partner were categorized as first, second and third based on the perception of closeness and relationship by the respondent. A large proportion of encounters with first girlfriend were reported unprotected as $44 \%$ respondents reported never using condom with this partner whereas only 4 percent reported every time condom use (Table 2).

\section{Conclusions and Recommendations}

The nature of sex and romantic relations seems to be changing. The concept of true love is fast being replaced by casual sex. Premarital sex is on the rise. Importantly, alcohol use before sex is also high among these youth. Sexual relationships are often devoid of love and commitments. Cravings for immediate carnal pleasure with less concern for its negative fall outs seem to have paved the way for casual sex with not only unmarried girls but also with married women often from the same neighborhood. The tendency of imbibing the sexual culture of the affluent by these youth in low-income slums probably indicates a newer trend. It requires further exploration not only just from the risk perspective but also from the social and psychological changes that usher in. It was amply clear that influence of peer plays a crucial role in blurring the line between simple friendships and friendships with a benefit. It also needs greater understanding of the other possible factors that aid to this changing sexual behavior. It is important to unearth whether this is restricted only to youth in the slums of metropolis in India or the same phenomena has been increasingly more common in other parts of the society. Undoubtedly, the youth in the metropolitan areas enjoy more anonymity with higher opportunity to mix freely with girls. They are also exposed to a variety of sexual avenues which probably act as a trigger for indulging in higher sexual activities. Although they belong to a low-income strata but they have relatively higher ability to spend a portion of their income for sexual pleasure, be it paid sex or having casual sexual ties.

Apart from the changing nature of values around sexual relationship, the increasing indulgence in casual sex may put them to higher pedestal of risk of acquiring infections if the extent of condom use goes down. The findings have clearly suggested that with the increasing number of sexual partners, the reported condom use has been on the decline. It is especially true for young men as they have more freedom and social power. The self-assessment as sexual partner is strongly affecting the behavior and sexual liaisons. The relational satisfaction is also crucial as it has direct bearing not only on multiple partner behavior but also on coercive sex and sexual experimentations. Gone are the days when behavior could be changed through the strict societal norms and restriction in the form of cultural taboos. As also reflected in many narratives, youth today is fast changing and developing rebel to conservativeness of society. Thus, the policy makers need to put focused attentiveness on the needs and well-being of youth. The findings highlight the need for program interventions to ensure that youth are fully informed and equipped to make safe choices and negotiate wanted outcomes, while positively influencing their peer networks. Findings

\begin{tabular}{|c|c|c|c|c|c|c|}
\hline & \multicolumn{2}{|c|}{ Condom use attitude } & \multicolumn{2}{|c|}{ Total no. of sexual partner in last 12 months } & \multicolumn{2}{|c|}{ Coercive sex with girlfriend ever in last 6 months } \\
\hline & More positive & Moderately positive & 1-2 partners & 3 or more partners & No & Yes \\
\hline \multicolumn{7}{|c|}{ Relationship satisfaction with girlfriend } \\
\hline Not satisfied & 47.6 & 52.4 & 52.4 & 47.6 & 42.9 & 57.1 \\
\hline Satisfied & 26.9 & 73.1 & 76.9 & 23.1 & 61.5 & 38.5 \\
\hline \multicolumn{7}{|c|}{ Communication relationship with girlfriend } \\
\hline Less open & 33.3 & 66.7 & 33.3 & 66.7 & 33.3 & 66.7 \\
\hline Moderately open & 25 & 75 & 70.8 & 29.2 & 62.5 & 37.5 \\
\hline More open & 50 & 50 & 65 & 35 & 45 & 55 \\
\hline \multicolumn{7}{|c|}{ Self-assessment as sexual partner } \\
\hline Not satisfactory & 40 & 60 & 40 & 60 & 33.3 & 66.7 \\
\hline Somewhat satisfactory & 33.3 & 66.7 & 59.3 & 40.7 & 50 & 50 \\
\hline Satisfactory & 44.4 & 55.6 & 70.4 & 29.6 & 60 & 40 \\
\hline Total & 36.2 & 63.8 & 66 & 34 & 53.2 & 46.8 \\
\hline
\end{tabular}

Table 2: Percentages of males showing the effect of perceived relational satisfaction indicators on the safe sexual attitude and coercive sex. 
Citation: Singh SK, Sharma N, Mondol S, Siddhanta A (2014) True Love and Time Pass: Sexual Behavior of Metropolitan Slum Youth in India. J AIDS Clin Res 5: 341. doi:10.4172/2155-6113.1000341

also highlight the importance of peer networks which can have a positive or negative impact on the safety and wantonness of young people's relationships.

\section{Limitations of the Study}

As potentiallimitations of our study, sample may have underreported their romantic, physical and sexual experiences since such relationships are usually carried on secretly or talked less about openly. Secondly, the study was conducted among young males. Inclusion of females would have strengthened the study findings with complementary views and triangulation.

${ }^{*}$ Daru: Alcohol

${ }^{*}$ Burkha: A loose piece of clothing that covers the head and body completely except for a space for the eyes.

${ }^{* * *}$ Dupatta: A length of material worn arranged in two folds over the chest and thrown back around the shoulders.

\section{References}

1. Zimmer-Gembeck MJ (2002) The development of romantic relationships and adaptations in the system of peer relationships. J Adolesc Health 31: 216-225.

2. Furman $W$, Shaffer $L(2003)$ The role of romantic relationships in adolescent development. In Florsheim P (Ed.), Adolescent romantic relations and sexual behavior: Theory, research, and practical implications Mahwah: Erlbaum.

3. Brown BB (1999) "You're going out with whom?" Peer group influences on adolescent romantic relationships. In Furman W, Brown BB, Feiring C (Eds.) The development of romantic relationships in adolescence. Cambridge University Press, NewYork, 291-329.

4. Crockett LJ, Raffaelli M, Moilanen KL (2003) Adolescent Sexuality: Behavior and Meaning. In Adams G, Berzonsky M (Eds.), Blackwell handbook of adolescence. Malden, Blackwell, 393-412.

5. Diamond LM, Savin-Williams RC (2003) The intimate relationships of sexual minority youths. In Adams G, Berzonsky M (Eds.), Blackwell handbook of adolescence. Malden: Blackwell, 393-412.

6. Lefkowitz ES, Gillen MM (2006) "Sex is just a normal part of life": Sexuality in emerging adulthood. In Arnett JJ, Tanner JL (Eds.), Emerging adults in America: Coming of age in the 21st century. Washington, APA, 235-256.

7. Welsh DP, Rostosky SS, Kawaguchi MC (2000) A normative perspective of adolescent girls' developing sexuality. In Travis CB, White JS (Eds.), Sexuality, society, and feminism: Psychological perspectivs on women. Washington, APA 111-140.

8. Furman $W$, Shaffer $L(2006)$ The slippery nature of romantic relationships: Issues in definition and differentiation. In Crouter A, Booth A (Eds.), Romance and sex in adolescence and emerging adulthood: Risks and opportunities. Mahwah: Erlbaum, 171-178.

9. International Institute for Population Sciences and Macro International (2007) National Family Health Survey, 2005-06.

10. Dube L (1997) Women and Kinship: Comparative Perspectives on Gender in South and South-East Asia. United Nations University Press, New York.

11. Das V (1988) Femininity and the orientation to the body. In Chanana K (ed.), Socialization, Education and Women. Orient Longman, New Delhi, 193-207.

12. National AIDS Control Organization Annual Report, India, 2011.

13. National AIDS Control Organization Annual Report, India, 2012.

14. Jejeebhoy SJ, Sebastian MP (2004) Young people's sexual and reproductive health. In: Jejeebhoy SJ (Ed.), Looking Back, Looking Forward: A Profile of Sexual and Reproductive Health in India. Population Council, and Jaipur, India: Rawat Publications, New Delhi, 138-168.
15. Mehra S, Savithri R, Coutinho L (2002) Sexual behavior among un-married adolescents in Delhi, India: opportunities despite parental controls. Paper presented at the 2002 IUSSP Regional Population Conference, Bangkok.

16. Potdar R, Koenig MA (2005) Does Audio-CASI improve reports of risky behavior? Evidence from a randomized field trial among young urban men in India. Stud FamPlann 36: 107-116.

17. Abraham L, Kumar KA (1999) Sexual experiences and their correlates among college students in Mumbai City, India. International Family Planning Perspectives 25: 139-146.

18. Awasthi S, Nichter M, Pande VK (2000) Developing an interactive STD prevention program for youth: lessons from a north Indian slum. Stud FamPlann 31: 138-150.

19. Kaur U, Sahni SP, Bambery P, Kumar B, Chauhan A, et al. (1996) Sexua behaviour, drug use and hepatitis $B$ infection in Chandigarh students. Natl Med J India 9: 156-159.

20. Alexander M, Garda L, Kanade S, Jejeebhoy S, Ganatra B (2007) Correlates of Premarital Relationships Among Unmarried Youth in Pune District, Maharashtra, India. IntFam Plan Perspect 33: 150-159.

21. Family Planning Association of India (n.d.) Youth Sexuality: A Study of Knowledge, Attitudes, Beliefs and Practices among Urban Educated Indian Youth, 1993-1994. Bombay: Family Planning Association of India and Sex Education, Counseling, Research and Training.

22. Rakesh A (1992) Premarital Sexual Attitudes and Behavior among Adolescent Girls, Jaipur: Printwell.

23. Goparaju L (1993) Unplanned, unsafe: male student's sexual behavior. Paper presented at the work-shop on Sexual Aspects of AIDS/STD Prevention in India at Tata Institute of Social Sciences, Bombay.

24. Bhende A (1994) A Study of Sexuality of Adolescent Girls and Boys in Under privileged Groups in Bombay. The Indian Journal of Social Work 55: 557-571.

25. Rangaiyan $R$ (1995) Sexuality and sexual behavior in the age of AIDS: a study among college youth in Mumbai, Doctoral Dissertation, International Institute of Population Sciences, Mumbai.

26. Sachdev P (1997) University students in Delhi, India: their sexual knowledge attitudes and behavior. Journal of Family Welfare 43: 1-12.

27. Murthy MSR (1993) Sex Awareness among Rural Girls, BR Publishing Corporation, New Delhi.

28. Verma RK, Sureender S, Guruswamy M (1997) What do school children and teachers in rural Maharashtra think of AIDS and sex? Health Transit Rev 7 Suppl: 481-486.

29. Singh SK, Schensul JJ, Gupta K, Maharana B, Kremelberg D, et al. (2010) Determinants of alcohol use, risky sexual behavior and sexual health problems among men in low income communities of Mumbai, India. AIDS Behav 14 Suppl 1: S48-60.

30. Thapan M (1997) Embodiment: Essays on Gender and Identity. Oxford University Press, Delhi.

31. Abraham L (2002) Bhai-behen, true love, time pass: Friendships and sexual partnerships among youth in an Indian metropolis. Culture, Health \& Sexuality 4: 337-353. 